\title{
Effect of corrosion inhibitors on the rate of carbon steel dissolution in chloride solution under alternating current
}

\author{
T.A. Nenasheva ${ }^{(1) *}$ and A.I. Marshakov $(\mathbb{D}$ \\ A.N. Frumkin Institute of Physical Chemistry and Electrochemistry, Russian Academy \\ of Sciences, 119071 Moscow, Russian Federation \\ *E-mail: tnenasheva@rambler.ru
}

\begin{abstract}
The study covers the effect of two inhibitory organic formulations and sodium nitrite on the AC corrosion rate of carbon steel in $3.5 \% \mathrm{NaCl}$ aqueous solution. The weighing method was used to determine the corrosion rates at the free corrosion potentials or after electrode polarization at a potential of intense metal dissolution. It has been shown that the efficiency of the inhibitors studied decreases under alternating current. The degree of protection varies in the range from 30 to $70 \%$ depending on the alternating current density (peak potential values). It is assumed that the decrease in degree of inhibitory protection in the case of $\mathrm{AC}$ corrosion is due to a decrease in the efficiency of inhibitors over time under conditions of intense metal dissolution. It has been shown that the concentration of $\mathrm{Fe}(\mathrm{II})$ compounds in the $\mathrm{AC}$ corrosion products grows proportionately with an increase in the steel mass loss. In the presence of organic inhibitors, the concentration of $\mathrm{Fe}$ (II) compounds grows considerably and no linear correlation with the mass loss of steel is observed. It is assumed that the "oxide-free" metal passivation in the presence of organic corrosion inhibitors may be the reason of the increase in the amount of $\mathrm{Fe}(\mathrm{II})$ compounds in the $\mathrm{AC}$ corrosion products.
\end{abstract}

Received: July 27, 2021. Published: August 18, 2021

doi: $\underline{10.17675 / 2305-6894-2021-10-3-16}$

Keywords: corrosion, alternating current, carbon steel, chloride electrolyte, organic corrosion inhibitors, nitrite, mass loss, potentiostatic polarization, coulometric oxidation, passivation.

\section{Introduction}

The corrosion of carbon and low-alloyed steels under the effect of alternating current (AC corrosion) is one of the most hazardous kinds of the corrosion damage of metal structures operating in soils or in natural water environments. It has been shown repeatedly that the AC corrosion is especially dangerous in a defect of a pipeline insulation coating, since in this case the alternating current density $\left(i_{\mathrm{AC}}\right)$ may reach considerable values $[1,2]$. The highest $i_{\mathrm{AC}}$ values should be observed in highly conductive environments such as saline soils or sea water, where the AC corrosion rate may reach a few $\mathrm{mm} /$ year [3-9].

One of the most common ways for the protection of metals against corrosion involves the use of inhibitors. Various organic and inorganic compounds are currently used as 
corrosion inhibitors (CIs). In particular, the use of coatings containing CIs [10-12] is recommended for enhancing the efficiency of corrosion protection of the outer walls pipelines. In cases where the insulation coating integrity is lost and the pipeline metal contacts a soil (underfilm) electrolyte, a CI is transferred to the corrosion environment and provides steel protection against corrosion. It has been shown that some organic compounds efficiently slow the cathodic and anodic reactions involved in the pipeline steel corrosion in model underfilm (soil) electrolytes [10] and prevent the buildup of local corrosion damage such as stress corrosion cracking [13] and pitting corrosion [14-15]. Model underfilm electrolytes are low-concentrated salt solutions. For example, the total concentration of corrosive $\mathrm{Cl}^{-}$and $\mathrm{SO}_{4}^{2-}$ ions in NS4 solution [16] equals $10.27 \mathrm{mM}$. Due to low electrical conductivity, the risk of $\mathrm{AC}$ corrosion in such media is insignificant, especially under a delaminated pipeline coating. However, the regularities of AC corrosion of steels in concentrated chloride electrolytes such as sea water have been studied insufficiently [4, 17].

As a rule, the protective capability of a CI is measured at the free corrosion potential of a metal, at a constant anodic potential (current) or by recording polarization curves. In the latter case, the CI effect on the rate of cathodic and anodic reactions is studied in rather a wide range of potentials. We found no studies of the CI protective efficiency in AC corrosion of steels in the available literature. At the same time, the AC corrosion of steels has some specifics to be taken into account when choosing a CI. For example, it has been found that as the alternating current density increases, the corrosion potential moves in the negative direction [18-20] and reaches values that correspond to the region of cathodic protection potentials for steel structures ( $E \leq-0.85 \mathrm{~V}$ versus the copper-sulphate reference electrode) [21].

At present, the mechanism of AC corrosion of steels is a matter of discussion [22-24]. The majority of authors believe that the specifics of AC corrosion of steels in soils and natural waters (i.e. in electrolytes with nearly neutral $\mathrm{pH}$ ) is explained by a considerable $\mathrm{pH}$ growth in the near-electrode solution layer during the cathodic $\mathrm{AC}$ half-cycle. According to the reported concept $[25,26]$, during the anodic AC half-cycle, formation of a Fe(III) oxide layer and passivation of the metal occur. During the cathodic half-cycle, a passive film is reduced to $\mathrm{Fe}$ (II) hydroxide/oxide whose layer has no protective properties. During the next anodic cycle, the Fe(II) compounds are not oxidized, and a new passive film grows on the metal surface. Reduction of the newly formed passive film increases the concentration of $\mathrm{Fe}$ (II) compounds. As a result, some amount of the metal is oxidized during every cycle, which results in considerable AC corrosion [25]. The reason of AC corrosion may also lie in steel dissolution in a strongly alkaline environment to give $\mathrm{HFeO}_{2}^{-}$ions according to the Pourbaix diagram, but this mechanism should function at very negative potentials of electrochemical protection of the structure, i.e. at very high densities of DC cathodic current $[27,28]$. It is assumed that hydrogen absorbed by the metal may also contribute to faster steel dissolution in AC corrosion [4, 29, 30]. 
Therefore, the specific features of AC corrosion, such as the alternating polarity, increase in near-electrode $\mathrm{pH}$, hydrogen absorption-desorption from the metal and a shift of corrosion potential in the negative direction, may affect the efficiency of inhibitory protection. For this reason, this study aimed at examining the effect of various CI types on the AC corrosion rate of carbon steel in a chloride electrolyte simulating sea water. Natural sea water is rather a complex system whose corrosivity depends on various physical, chemical and biological factors. Therefore, simulation of natural sea water for corrosion tests under laboratory conditions presents certain difficulties. Usually, solutions of synthetic sea water [5, 31-34] or $\mathrm{NaCl}$ solutions $(1.85,3.5$ or 5\%) [6, 35-37] are employed to study the corrosion behavior of steel in sea water. It is known that $\mathrm{NaCl}$ solutions are more corrosive than natural sea water, especially to carbon steel $[38,39]$. In this study, a $3.5 \% \mathrm{NaCl}$ solution was chosen as the testing environment to simulate sea water.

\section{Experimental}

The tests were performed on electrodes $0.2 \mathrm{~mm}$ thick with a working area of $\left(7-10 \mathrm{~cm}^{2}\right)$ made of $08 \mathrm{kp}$ carbon steel, the elemental composition of which is as follows, (wt \%: C, 0.05; $\mathrm{Si}, 0.03 ; \mathrm{Mn}, 0.38 ; \mathrm{Ni}, 0.09 ; \mathrm{S}, 0.04 ; \mathrm{P}, 0.035 ; \mathrm{Cr}, 0.05$; and $\mathrm{Cu}, 0.15$; the rest is iron). To remove the cold-worked metal layer, the electrode was chemically etched in $15 \% \mathrm{HCl}$ solution for 10 minutes, rinsed in distilled water, and dried before the experiment. A strip of foil from steel of the same grade served as a current lead to the electrode. Electrical contact was performed by connecting the electrode and current lead with a clamp made of an inert material, which was fully submerged into the solution to avoid the growth of metal corrosion losses at the air/electrolyte interface. To remove the corrosion products from the surface after the experiment, the samples were etched for $2 \mathrm{~min}$ in $15 \% \mathrm{HCl}$ solution containing $0.5 \%$ urotropin, rinsed in distilled water, and dried. The weighing method was used to determine the metal mass loss after keeping the samples in the solution at the free corrosion potential for 24 hours or after one-hour electrode polarization at a potential of $E=-0.15 \mathrm{~V} v s$. SHE.

The effect of alternating sine-wave current $(50 \mathrm{~Hz})$ on the metal corrosion rate was examined in a cell with two identical steel electrodes and two silver-chloride reference electrodes with a Luggin capillary. The voltage between the steel electrodes was set with a stabilized alternating voltage source, a step-down transformer, and a voltage divider. The sample was polarized for 24 hours. The potential amplitude (peak value, $E_{\mathrm{p}}$ ) was varied from 0.4 to $1.5 \mathrm{~V}$, while the effective alternating current averaged over the test time ( $\left.i_{\mathrm{eff}}\right)$ was varied from 0.015 to $0.077 \mathrm{~A} / \mathrm{cm}^{2}$. The correlation between $E_{\mathrm{p}}$ and $i_{\text {eff }}$ in similar tests was reported elsewhere [4]. However, the relationship between AC current density and peak potential was shown to change over time due to an increase in the pseudo-capacitance of the electrode. In this regard, the $\underline{i}_{\text {eff }}$ values cannot unambiguously characterize the effect of alternating current on the rate of metal dissolution and it is more valid to determine the rate of $\mathrm{AC}$ corrosion at a constant $E_{\mathrm{p}}$ value [4].

For electrochemical studies, a three-electrode cell with a platinum auxiliary electrode and a silver-chloride reference electrode with a Luggin capillary were used. The electrode 
potentials are given versus SHE. Potentiodynamic polarization curves $(1 \mathrm{mV} / \mathrm{s})$ were recorded from -1.1 to $0.2 \mathrm{~V}$ with an IPC - Pro - MF potentiostat.

The concentration of Fe(II) compounds in steel corrosion products was determined by the chronopotentiometric method, also known as the coulometric oxidation method [25]. After polarization by alternating current, the sample was rinsed in $0.1 \mathrm{M} \mathrm{NaOH}$ solution, transferred to a standard three-electrode cell with the same alkali solution, and the variation of potential over time at a constant anodic current density of $0.1 \mathrm{~mA} / \mathrm{cm}^{2}$ was recorded.

The inhibitor efficiency (degree of corrosion protection) was estimated as:

$$
Z=\frac{\left(i_{\mathrm{a}, 0}-i_{\mathrm{a}, \mathrm{inh}}\right)}{i_{\mathrm{a}, 0}} \cdot 100 \%=\frac{\left(V_{0}-V_{\mathrm{inh}}\right)}{V_{0}} \cdot 100 \%
$$

where $i_{\mathrm{a}, 0}, V_{0}$, and $i_{\mathrm{a}, \mathrm{inh}}, V_{\mathrm{inh}}$ are the corrosion rates of steel (or anodic current densities) in the reference solution and in the presence of an inhibitor.

Several organic inhibitors were chosen to study the steel protection efficiency under the conditions of AC corrosion in a chloride solution. The CI-1 formulation is a mixture of products of reaction of fatty amines with various mixtures of higher unsaturated carboxylic acids, their ethers, and modifying additives [40]. This inhibitor was recommended for addition to a primer of polymeric-bitumen coatings for main gas lines [10]. The CI-2 formulation is a mixture of flufenamic acid $\left.\left(3-\left(\mathrm{CF}_{3}\right) \mathrm{C}_{6} \mathrm{H}_{4} \mathrm{NH}\right] \mathrm{C}_{6} \mathrm{H}_{4} \mathrm{COOH}\right)$ anions and sodium oleate $\mathrm{CH}_{3}\left(\mathrm{CH}_{2}\right)_{7} \mathrm{CH}=\mathrm{CH}\left(\mathrm{CH}_{2}\right)_{7} \mathrm{COONa}$ ) [41]. It has been shown that $\mathrm{CI}-2$ is an efficient inhibitor in neutral aqueous solutions [42-44], including those containing chlorides [44]. Captax is 2-mercaptobenzothiazole $\left(\mathrm{C}_{7} \mathrm{H}_{5} \mathrm{NS}_{2}\right)$, which is a corrosion inhibitor for ferrous metals in neutral aqueous solutions of salts [45,46] and [47]. Triazole-based compounds are efficient corrosion inhibitors in $3.5 \% \mathrm{NaCl}$ solution [48]. To compare the protective efficiency of organic and inorganic CIs, sodium nitrite was chosen as a representative of the latter. Nitrite ions are rather efficient CIs of carbon steels in alkaline chloride-containing media [49-53].

A $3.5 \% \mathrm{NaCl}$ solution was used as the reference electrolyte. All solutions were prepared using distilled water. The concentrations in CI-1, CI-2, Captax and nitrite solutions were $1 \mathrm{~g} / 1,5 \mathrm{mM}, 5 \mathrm{mM}$ and $1 \mathrm{mM}$, respectively. The additives were introduced as concentrated aqueous or alcoholic solution. The tests were performed at room temperature $\left(20 \pm 2^{\circ} \mathrm{C}\right)$ with free access of oxygen.

\section{Results and Discussion}

\subsection{Effect of corrosion inhibitors on steel dissolution rate in the absence of AC polarization}

Figure 1 shows the anodic and cathodic polarization curves (PC) in the reference solution and in the presence of various inhibiting additives. First, polarization curves were recorded with a potential sweep toward less positive values (forward PC scan from $-1.1 \mathrm{~V}$ to $0.2 \mathrm{~V}_{\mathrm{SHE}}$ ) (Figure 1a), then in the opposite direction (reverse PC scan from 0.2 to $-1.1 \mathrm{~V}_{\mathrm{SHE}}$ ) 
(Figure 1b). As one can see, in the presence of CI-1, CI-2 mixtures or $\mathrm{NaNO}_{2}$, the steel corrosion potential shifts positively by 100 to $200 \mathrm{mV}$, whereas the addition of Captax to the reference solution shifts $E_{\text {corr }}$ slightly to the negative side. At cathodic potentials, the CI-1 mixture or Captax have no significant effect on the process rate, whereas addition of the CI-2 mixture or sodium nitrite to the solution results in a slight growth of cathodic current. All the additives reduce the anodic current during the forward PC scan, but their efficiency differs (Figure 1a). During the reverse PC scan, the efficiency of inhibitors generally decreases (Figure 1b). Table 1 shows the values of anodic current density $\left(i_{\mathrm{a}}\right)$ at $E=-0.15 \mathrm{~V}_{\text {SHE }}$ (at this potential, the cathodic reaction rate should be low compared to the anodic current) determined during the forward and reverse PC scans. Captax nearly does not slow down the anodic steel dissolution (Figure 1 and Table 1), so it was not used in the subsequent tests.
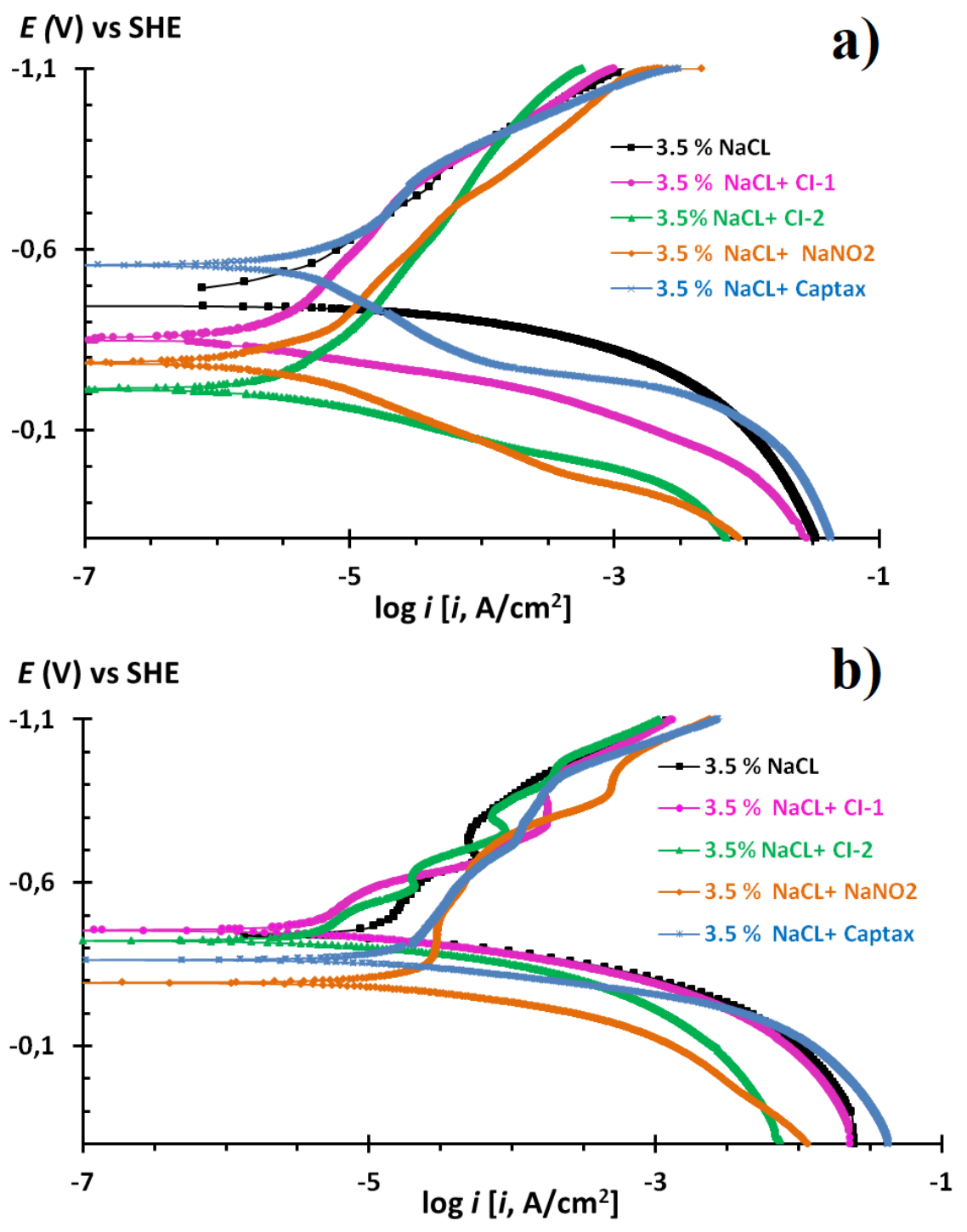

Figure 1. Potentiodynamic polarization curves in solutions with various compositions: a) forward scan; b) reverse scan. 
Table 1. Anodic current density at $E=-0.15 \mathrm{~V}_{\mathrm{SHE}}$ found during forward and reverse PC scans in solutions with various compositions.

\begin{tabular}{ccc}
\hline \multirow{2}{*}{ Solution } & \multicolumn{2}{c}{$\boldsymbol{i}_{\mathbf{a}, \mathbf{A} / \mathbf{c m}^{2}}$} \\
\cline { 2 - 3 } & Forward scan & Reverse scan \\
$3.5 \% \mathrm{NaCl}$ & $7.24 \cdot 10^{-3}$ & $7.94 \cdot 10^{-3}$ \\
$3.5 \% \mathrm{NaCl}+\mathrm{CI}-1$ & $7.94 \cdot 10^{-4}$ & $5.89 \cdot 10^{-3}$ \\
$3.5 \% \mathrm{NaCl}+\mathrm{CI}-2$ & $1.34 \cdot 10^{-5}$ & $5.13 \cdot 10^{-3}$ \\
$3.5 \% \mathrm{NaCl}+\mathrm{NaNO} 2$ & $2.57 \cdot 10^{-5}$ & $7.08 \cdot 10^{-4}$ \\
$3.5 \% \mathrm{NaCl}+\mathrm{Captax}$ & $7.28 \cdot 10^{-3}$ & $7.9 \cdot 10^{-3}$ \\
\hline
\end{tabular}

As follows from Table 1, the anodic current values found from a reverse PC scan may be several tens of times smaller than those recorded during a forward PC scan. This phenomenon may be related to a decrease in $\mathrm{CI}$ efficiency over time under the conditions of intense metal dissolution and should be taken into account under AC corrosion conditions.

To estimate how the protective action of inhibitors changes over time, the variation of anodic current was recorded for one hour at $E=-0.15 \mathrm{~V}_{\mathrm{SHE}}$ (Figure 2). The change in the protection degree $(Z)$ over time was calculated from the data of Figure 2 using Equation (1). As one can see, all the inhibitors show high efficiency in the beginning, the $Z$ value becomes 2 to 3 times smaller with time, and in the end of the test it is 30 to $40 \%$ (Figure 3). The mean steel dissolution rate $(V)$ during the test was found from the mass loss data (Table 2). It should be noted that the mean steel dissolution rate calculated by the electrode mass loss and by integrating the "anodic current - time" curves (Figure 2) agree satisfactorily. In fact, the metal dissolution rates in the reference solution (in current units) calculated from the mass loss and from the quantity of electricity are $6.97 \cdot 10^{-3}$ and $6.84 \cdot 10^{-3} \mathrm{~A} / \mathrm{cm}^{2}$, respectively.

Table 2. Steel dissolution rate $(V)$ at $E=-0.15 \mathrm{~V}_{\mathrm{SHE}}$ and protection degree of inhibitors $(Z)$ in solutions with various compositions.

\begin{tabular}{ccc}
\hline Solution & $\boldsymbol{V}, \mathbf{g} /\left(\mathbf{m}^{\mathbf{2}}\right.$ day $)$ & $\boldsymbol{Z}, \boldsymbol{\%}$ \\
\hline $3.5 \% \mathrm{NaCl}$ & 73.78 & - \\
$3.5 \% \mathrm{NaCl}+\mathrm{CI}-1$ & 33.58 & 54 \\
$3.5 \% \mathrm{NaCl}+\mathrm{CI}-2$ & 34.26 & 52 \\
$3.5 \% \mathrm{NaCl}+\mathrm{NaNO}_{2}$ & 34.63 & 53 \\
\hline
\end{tabular}




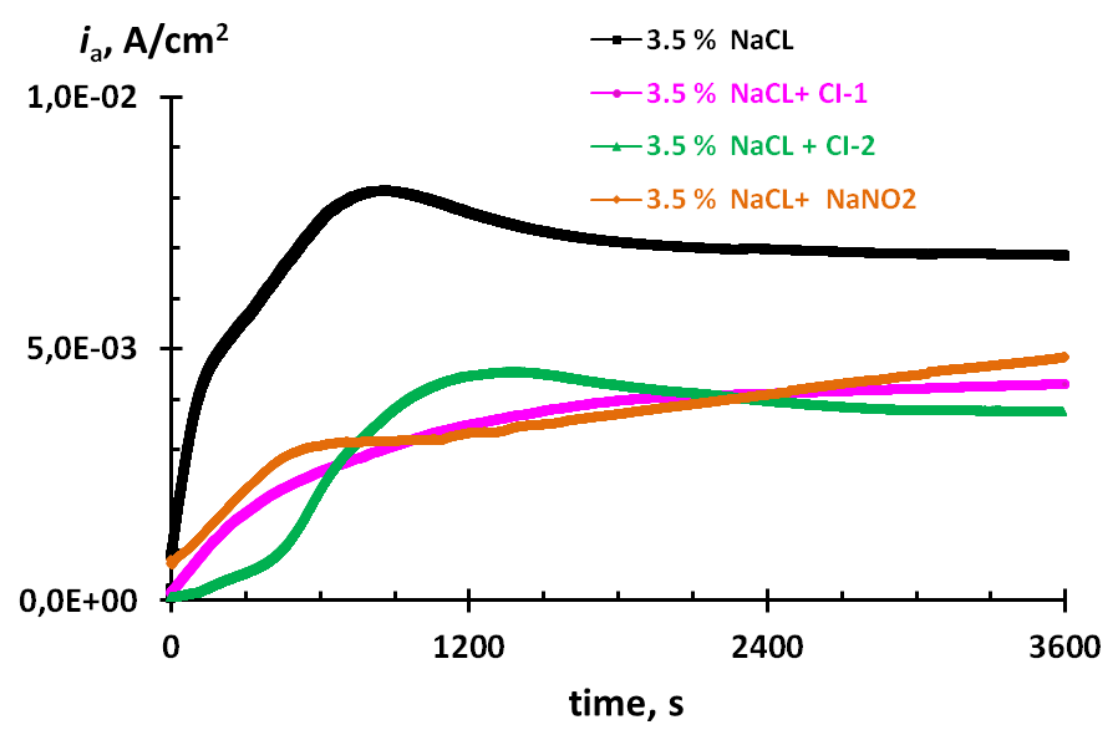

Figure 2. Variation of anodic current density over time at $E=-0.15 \mathrm{~V}_{\mathrm{SHE}}$ in solutions with various compositions.

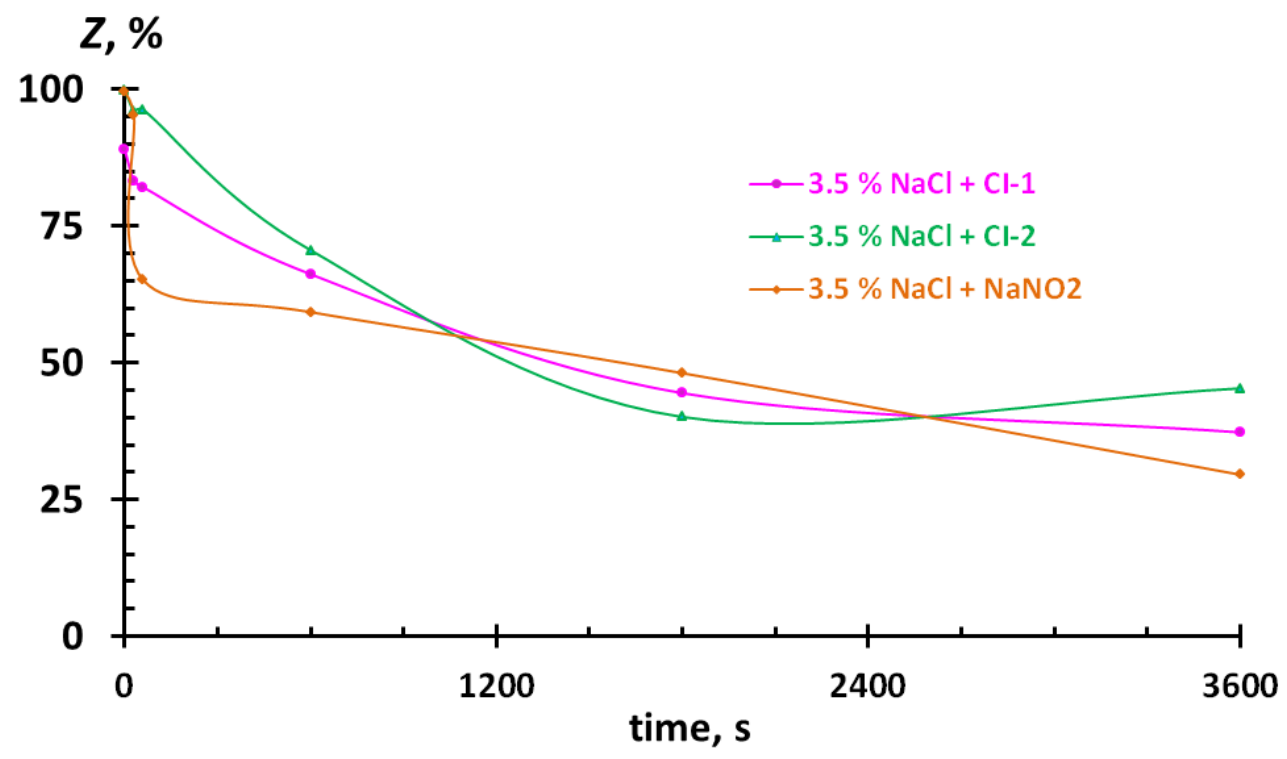

Figure 3. Change of the protection degree of corrosion inhibitors $(Z)$ over time in solutions with various compositions. $E=-0.15 \mathrm{~V}_{\mathrm{SHE}}$.

In the presence of all the CIs studied, the steel dissolution rates calculated from the mass loss are roughly the same, $Z=52$ to $54 \%$ (Table 2 ).

Therefore, under the conditions of intense steel dissolution in the chloride electrolyte, the protection degree provided by the CIs studied decreases with time. However, the $Z$ value remains practically significant; both the organic CIs and nitrite decrease the steel mass loss approximately twofold. 


\subsection{AC corrosion of steel in inhibited solutions}

The study on the effect of alternating current on the steel corrosion rate in solutions with addition of various corrosion inhibitors was performed at the corrosion potential, both in the absence of alternating current $\left(E_{\mathrm{p}}=0\right)$ and with various peak potential values. The samples were exposed for 24 hours in each mode. The variation in the steel corrosion potential in the course of the experiments was recorded. Table 3 shows the $E_{\text {corr }}$ values measured in the first minutes of the test (numerator) and after 24 hours (denominator). The $E_{\text {corr }}$ value in the denominator may be taken as the steady-state corrosion potential. In the reference solution and in the presence of all the CIs, the steel corrosion potential shifts in the negative direction with an increase in $E_{\mathrm{p}}$. This phenomenon observed in various corrosive media is explained by the acceleration of the anodic process due to the faradaic rectification of alternating current [4]. As a rule, $E_{\text {cor }}$ increases in the course of a test; it was explained by a growth of the thickness of a layer of poorly conductive corrosion products and an increasing ohmic component of $E_{\mathrm{p}}$ [54]. As shown in Table 3, the addition of CIs to a solution shifts $E_{\text {corr }}$ to less negative values.

We will estimate the shift of the steady-state corrosion potential (after 24 hours) as:

$$
\Delta E_{\text {corr }}=E_{\text {corr,CI }}-E_{\text {corr, } \mathrm{b}}
$$

where $E_{\text {corr,b }}$ and $E_{\text {corr,CI }}$ are the potentials in the reference solution and in the presence of a CI, respectively.

Since the CIs under study mainly slow down the anodic reaction (Figure 1), we could have expected that the positive value of $\Delta E_{\text {corr }}$ would correlate with the protective efficiency of the inhibitors. In fact, linear correlation between $\Delta E_{\text {corr }}$ values and $Z$ values calculated from $i_{\mathrm{a}}$ values measured after 1 hour of electrode anodic polarization is observed in the absence of alternating current (Figure 3) and (Figure 4).

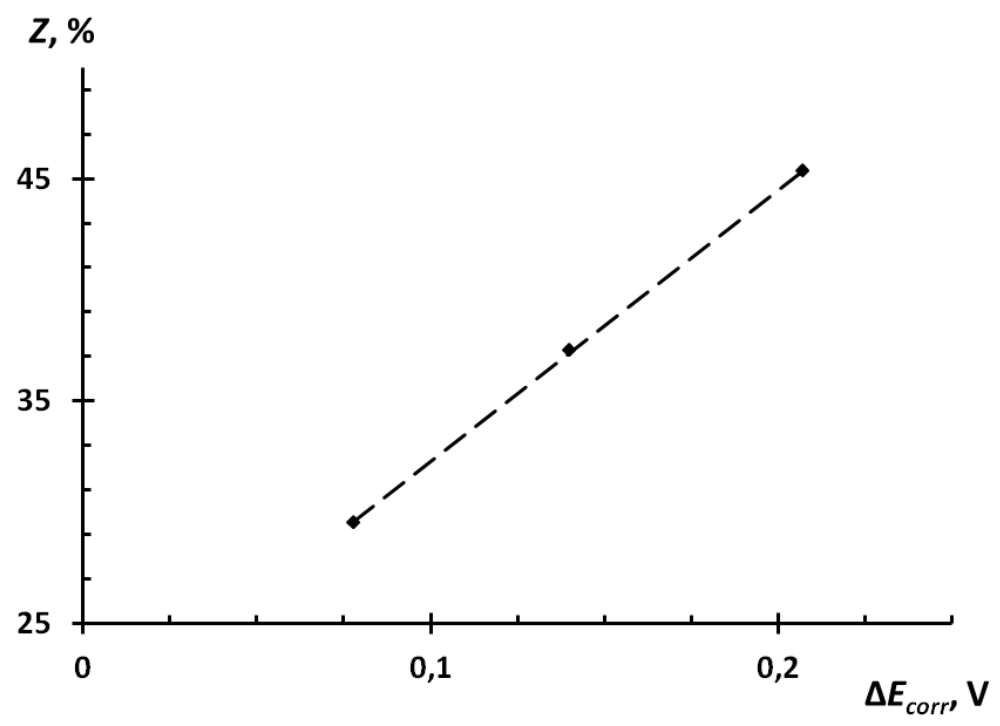

Figure 4. Comparison of $\Delta E_{\text {corr }}$ and $Z$ values in inhibited solutions. 
Table 4 shows the rates of AC corrosion found by the gravimetric method (numerator) and the corresponding $Z$ values (denominator). As one can see, all the CIs studied slow down the steel corrosion rate both without and with alternating current. Nevertheless, there is no correlation between $\Delta E_{\text {corr }}$ (Table 3 ) and $Z$ values found from mass loss data (Table 4). It should be due to the fact that $Z$ value changes considerably over time not only under anodic polarization but also at the corrosion potential, while the mass loss method gives an averaged value of the steel corrosion rate.

Table 3. Corrosion potentials of steel $\left(E_{\text {corr }}\right)$ in the absence of alternating current $\left(E_{p}=0\right)$ and at two values of peak potential $\left(E_{p}\right)$ measured in the first minutes of the test (numerator) and after 24 hours (denominator).

\begin{tabular}{|c|c|c|c|c|c|c|}
\hline \multirow{2}{*}{ Solution } & \multicolumn{3}{|c|}{$E_{\text {corr }}, \mathbf{V}$} & \multicolumn{3}{|c|}{$\Delta E_{\mathrm{corr}}, \mathrm{V}$} \\
\hline & $E_{\mathrm{p}}=0$ & $E_{\mathrm{p}}=0.5$ & $E_{\mathrm{p}}=1.4$ & $E_{\mathrm{p}}=0$ & $E_{\mathrm{p}}=0.5$ & $E_{\mathrm{p}}=1.4$ \\
\hline \multirow{2}{*}{$3.5 \% \mathrm{NaCl}$} & -0.467 & -0.694 & -0.707 & & & \\
\hline & $\overline{-0.470}$ & $\overline{-0.569}$ & $\overline{-0.640}$ & & & \\
\hline \multirow{2}{*}{$3.5 \% \mathrm{NaCl}+\mathrm{CI}-1$} & -0.310 & $\underline{-0.552}$ & $\underline{-0.625}$ & \multirow{2}{*}{0.14} & \multirow{2}{*}{0.106} & \multirow{2}{*}{0.13} \\
\hline & $\overline{-0.330}$ & $\overline{-0.463}$ & $\overline{-0.510}$ & & & \\
\hline \multirow{2}{*}{$3.5 \% \mathrm{NaCl}+\mathrm{CI}-2$} & -0.297 & $\underline{-0.477}$ & $\underline{-0.652}$ & \multirow{2}{*}{0.207} & \multirow{2}{*}{0.067} & \multirow{2}{*}{0.121} \\
\hline & $\overline{-0.263}$ & $\overline{-0.502}$ & $\overline{-0.519}$ & & & \\
\hline \multirow{2}{*}{$3.5 \% \mathrm{NaCl}+\mathrm{NaNO}_{2}$} & -0.253 & -0.584 & -0.632 & \multirow{2}{*}{0.078} & \multirow{2}{*}{0.099} & \multirow{2}{*}{0.164} \\
\hline & $\overline{-0.392}$ & $\overline{-0.470}$ & $\overline{-0.476}$ & & & \\
\hline
\end{tabular}

Table 4. Steel corrosion rates $(V)$ and protection degrees of CIs $(Z)$ in the absence of alternating current $\left(E_{\mathrm{p}}=0\right)$ and at various peak potentials $\left(E_{\mathrm{p}}\right)$.

\begin{tabular}{ccccc}
\hline \multirow{2}{*}{ Solution } & \multicolumn{4}{c}{$\mathbf{V , \mathbf { g } / ( \mathbf { m } ^ { 2 } \cdot \mathbf { d a y } )}$} \\
$\mathbf{Z}, \boldsymbol{\%}$ & \\
\hline $3.5 \% \mathrm{NaCl}$ & $E_{\mathrm{p}=0}$ & $E_{\mathrm{p}}=0.5 \mathrm{~V}$ & $E_{\mathrm{p}}=1 \mathrm{~V}$ & $E_{\mathrm{p}=1.4 \mathrm{~V}}$ \\
\hline $3.5 \% \mathrm{NaCl}+\mathrm{Cl}-1$ & $\frac{1.95}{-}$ & $\frac{6.0}{-}$ & $\frac{10.18}{-}$ & $\frac{15.31}{-}$ \\
\hline $3.5 \% \mathrm{NaCl}+\mathrm{Cl}-2$ & $\frac{0.54}{72}$ & $\frac{4.16}{31}$ & $\frac{6.94}{32}$ & $\frac{7.63}{50}$ \\
\hline $3.5 \% \mathrm{NaCl}+\mathrm{NaNO}_{2}$ & $\frac{0.63}{68}$ & $\frac{1.59}{74}$ & $\frac{5.99}{41}$ & $\frac{7.32}{52}$ \\
\hline & $\frac{0.85}{56}$ & $\frac{3.96}{34}$ & $\frac{4.01}{61}$ & $\frac{6.65}{57}$ \\
\hline
\end{tabular}

If alternating current is imposed, the protection degree provided by the CIs generally decreases (Table 4). Rather a high value, $Z=74 \%$, at $E_{\mathrm{p}}=0.5 \mathrm{~V}$ in the presence of the CI-2 
formulation is an exception. It is possibly due to the fact that this CI is better adsorbed on an anodically activated steel surface $[41,55]$. However, with an increase in $E_{\mathrm{p}}$, the efficiency of CI-2 mixture also decreases. At the maximum value of $E_{\mathrm{p}}=1.4 \mathrm{~V}$, the protective effect of all the CIs studied is almost the same ( $Z=50$ to $57 \%$, Table 4) and coincides with the CI efficiency under the conditions of intense steel dissolution ( $Z=52$ to $54 \%$, Table 2$)$.

\subsection{Content of $\mathrm{Fe}(\mathrm{II})$ compounds in AC steel corrosion products}

Continuous conversion of the lowest layer of corrosion products adjacent to the metal occurs under the effect of alternating current $[26,56]$. During the anodic half-wave, a passive layer is formed which apparently consists mainly of $\mathrm{Fe}_{2} \mathrm{O}_{3}$ oxide; during the cathodic current halfcycle, the $\mathrm{Fe}$ (III) oxide is reduced to $\mathrm{Fe}(\mathrm{II})$ compounds. It has been shown that the concentration of $\mathrm{Fe}(\mathrm{II})$ compounds in the corrosion products of pipeline steel in soils correlates with the metal mass loss. It was even suggested to use the concentration of Fe(II) compounds for monitoring the corrosion rate of pipelines or for assessing the efficiency of anticorrosion measures [25].

Therefore, it seems of interest to study the relationship between the amount of $\mathrm{Fe}$ (II) in AC corrosion products and the corrosion rate in chloride media and with addition of CIs. The amount of $\mathrm{Fe}$ (II) was found by the chronopotentiometric method (also known as the coulometric oxidation method [25]) after polarization of an electrode for 24 hours in solutions with various compositions and at various $E_{\mathrm{p}}$ values. Figure 5 shows the plots of potential versus time obtained upon electrode polarization by an anodic current of $0.1 \mathrm{~mA} / \mathrm{cm}^{2}$ in $0.1 \mathrm{M}$ alkaline solution. As one can see, a slight potential growth is observed in the beginning, followed by a "plateau" on the $E, \tau$ curves. This potential delay should be due to the oxidation of $\mathrm{Fe}$ (II) to $\mathrm{Fe}$ (III) [25]. Subsequently, a steep increase in potential to values corresponding to oxygen evolution is observed. The times $\left(\tau_{\mathrm{Ox}}\right)$ of the potential delay on the $E, \tau$ curves are given in Table 5. The quantities of electricity $Q$ passed within time $\tau_{\text {Ox }}$ are also reported there.

Figure 6 shows the $Q$ values obtained at various $E_{\mathrm{p}}$ in the reference solution. As one can see, $Q$ increases with an increase in $E_{\mathrm{p}}$. The linear approximation of the $Q v s . E_{\mathrm{p}}$ plot has a satisfactory coefficient of determination $R^{2}=0.9$. At the same time, the $Q$ values depend not only on the AC amplitude but also on the solution composition. In the presence of CI-1 and CI-2 organic formulations, the $Q$ values at $E_{\mathrm{p}}=1-1.4 \mathrm{~V}$ are a few times higher than in the reference solution. The exponential plot of $Q v s$. $E_{\mathrm{p}}$ based on the data obtained in the solution containing CI- 1 has a coefficient of determination $R^{2}=0.98$. The $Q$ values obtained in the solution containing nitrite are roughly the same as in the reference solution.

Thus, at large AC amplitudes and in the presence of the organic CIs studied, the corrosion products contain more $\mathrm{Fe}$ (II) compounds than the products formed in the reference solution or in the presence of the oxidative CI (nitrite).

Since the $Q$ values were found by the coulometric oxidation method, it may be possible that organic CIs are located in pores of corrosion products and are oxidized during anodic polarization of the electrode. To exclude this effect, anodic polarization curves were 
recorded on steel in $0.1 \mathrm{M} \mathrm{NaOH}$ solution and with $\mathrm{CI}-1$ addition. It was found that the presence of CI-1 does not increase the anodic current (Figure 7), i.e., the organic CIs studied are resistant to oxidation at cathodic potentials.

Table 5. Time of potential delay ( $\left.\tau_{O x}\right)$, quantity of electricity $(Q)$ passed in time $\tau_{O x}$, mass of iron $\left(m_{O x}\right)$ in the reference solution and CI-containing solutions in the absence of alternating current $\left(E_{\mathrm{p}}=0\right)$ and in various AC polarization modes.

\begin{tabular}{|c|c|c|c|c|}
\hline Solution & $E_{\mathrm{p}}, \mathbf{V}$ & $\tau_{\text {Ox }}, \mathrm{s}$ & $Q, \mathrm{C}$ & $m_{0 x}, g /\left(m^{2} \cdot\right.$ day $)$ \\
\hline \multirow{7}{*}{$3.5 \% \mathrm{NaCl}$} & 0 & 3 & 0.0003 & 0.003 \\
\hline & 0.4 & 41 & 0.0041 & 0.025 \\
\hline & 0.5 & 45 & 0.0045 & 0.027 \\
\hline & 0.6 & 308 & 0.0308 & 0.147 \\
\hline & 0.7 & 462 & 0.0462 & 0.192 \\
\hline & 1 & 677 & 0.0677 & 0.392 \\
\hline & 1.4 & 671 & 0.0671 & 0.376 \\
\hline \multirow{5}{*}{$3.5 \% \mathrm{NaCl}+\mathrm{CI}-1$} & 0 & 22 & 0.0022 & 0.013 \\
\hline & 0.4 & 84 & 0.0084 & 0.046 \\
\hline & 0.5 & 160 & 0.016 & 0.097 \\
\hline & 1 & 1035 & 0.1035 & 0.598 \\
\hline & 1.4 & 2058 & 0.2058 & 1.186 \\
\hline \multirow{2}{*}{$3.5 \% \mathrm{NaCl}+\mathrm{CI}-2$} & 1 & 2587 & 0.2587 & 1.458 \\
\hline & 1.3 & 2787 & 0.2787 & 1.572 \\
\hline \multirow{4}{*}{$3.5 \% \mathrm{NaCl}+\mathrm{NaNO}_{2}$} & 1 & 293 & 0.0293 & 0.17 \\
\hline & 1.1 & 655 & 0.0655 & 0.376 \\
\hline & 1.3 & 409 & 0.0409 & 0.239 \\
\hline & 1.4 & 455 & 0.0455 & 0.27 \\
\hline
\end{tabular}

To correlate the concentration of Fe(II) compounds in the corrosion products with the metal mass loss $(m)$, the $Q$ values were recalculated into the mass of iron $\left(m_{\text {Ox }}\right)$ based on a single-electron reaction, since $Q$ corresponds to the $\mathrm{Fe}(\mathrm{II}) \rightarrow \mathrm{Fe}(\mathrm{III})$ oxidation. The $m_{\mathrm{Ox}}$ values are given in Table 5. Figure 8 compares the $m_{\mathrm{Ox}}$ and $m$ masses obtained at various $E_{\mathrm{p}}$ in the reference solution and in the presence of various CIs. As one can see, the $m_{\mathrm{Ox}}$ values are considerably smaller than $m$, i.e., the main fraction of the ionized metal passes into the electrolyte. In the reference solution, a linear correlation between $m_{\mathrm{Ox}}$ and $m\left(R^{2}=0.89\right)$ is observed, which agrees with the data obtained in soils [25]. In the presence of a CI, the concentration of $\mathrm{Fe}$ (II) compounds on the electrode surface becomes larger than in the 
reference solution. In particular, Figure 8 shows a correlation between $m_{\mathrm{Ox}}$ and $m$ in a solution with addition of the CI- 1 formulation (the logarithmic trendline with $R^{2}=0.96$ ). As one can see, at large mass losses, the concentration of Fe(II) compounds may be roughly 10 times larger in the presence of an organic CI than in the reference solution.

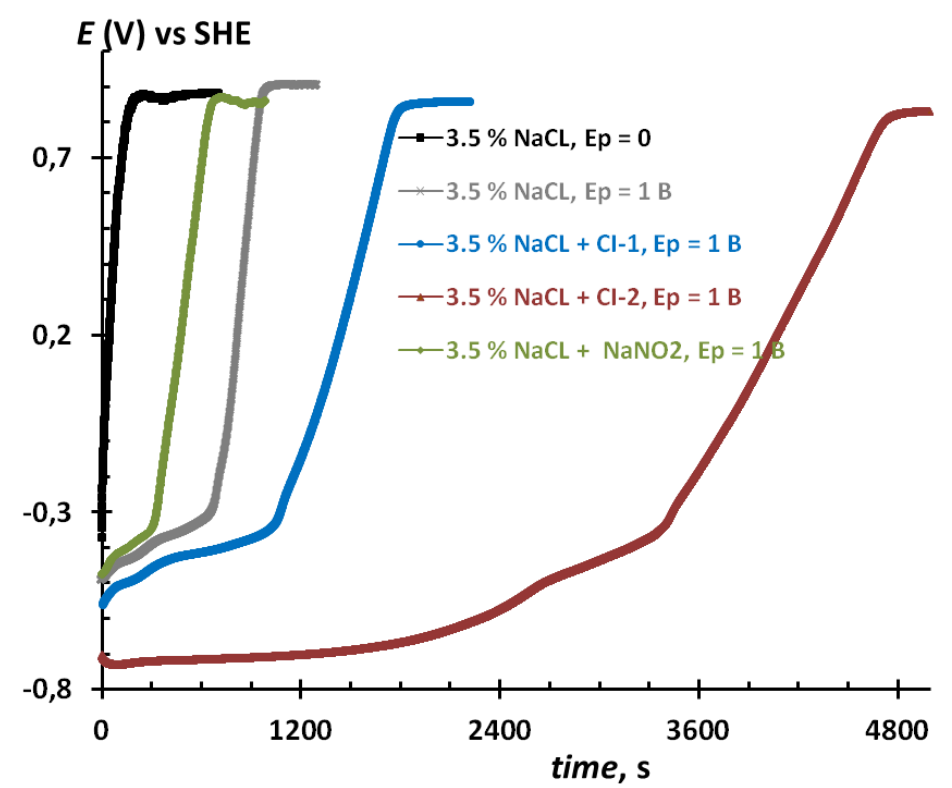

Figure 5. Change of potential over time in solutions with various compositions in the absence of alternating current $\left(E_{\mathrm{p}}=0\right)$ and with $E_{\mathrm{p}}=1 \mathrm{~V}$.

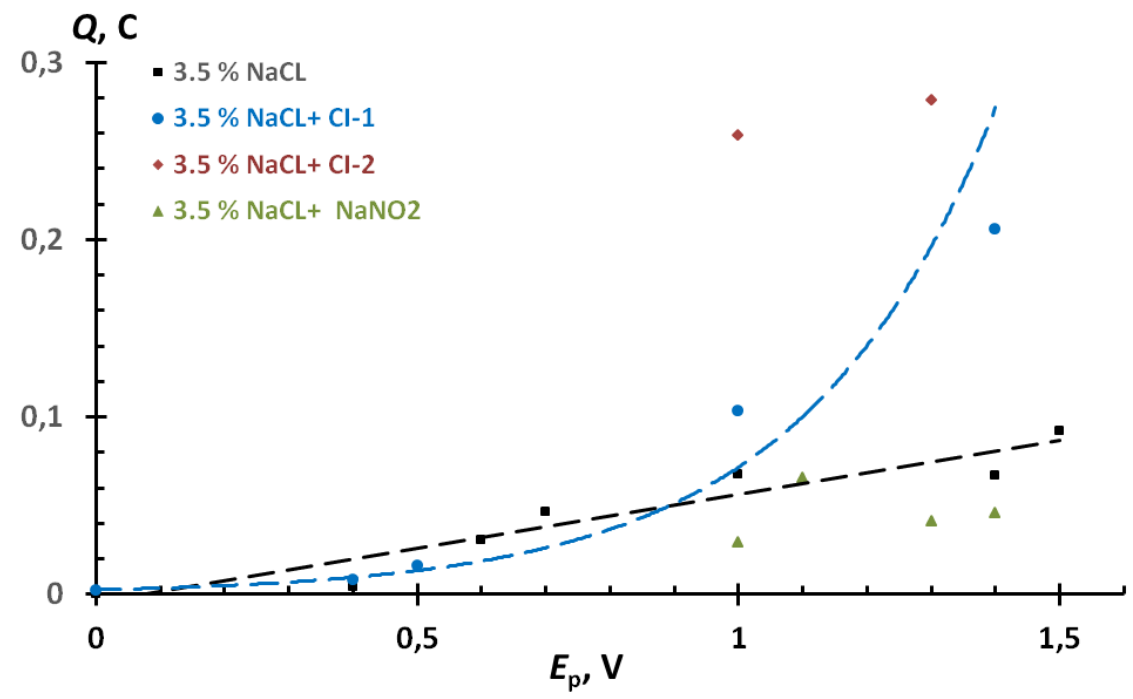

Figure 6. Plots of $Q v s . E_{\mathrm{p}}$ in solutions with various compositions.

This phenomenon can have a few explanations. Organic inhibitors can slow down the reaction of $\mathrm{Fe}$ (II) to $\mathrm{Fe}$ (III) oxidation in the corrosion products or the molization of hydrogen atoms on the metal surface. In the latter case, atomic hydrogen can reduce Fe(III) compounds to $\mathrm{Fe}(\mathrm{II})$ [18]. 


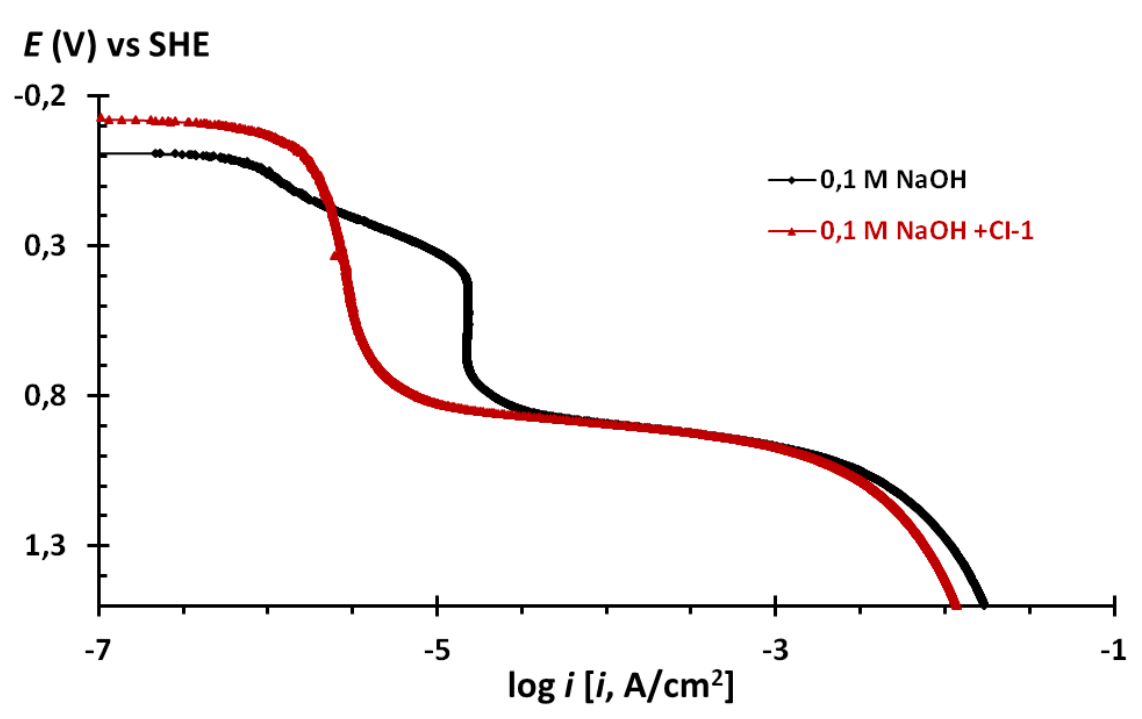

Figure 7. Potentiodynamic anodic polarization curves in $0.1 \mathrm{M} \mathrm{NaOH}$ solution and with CI-1 addition.

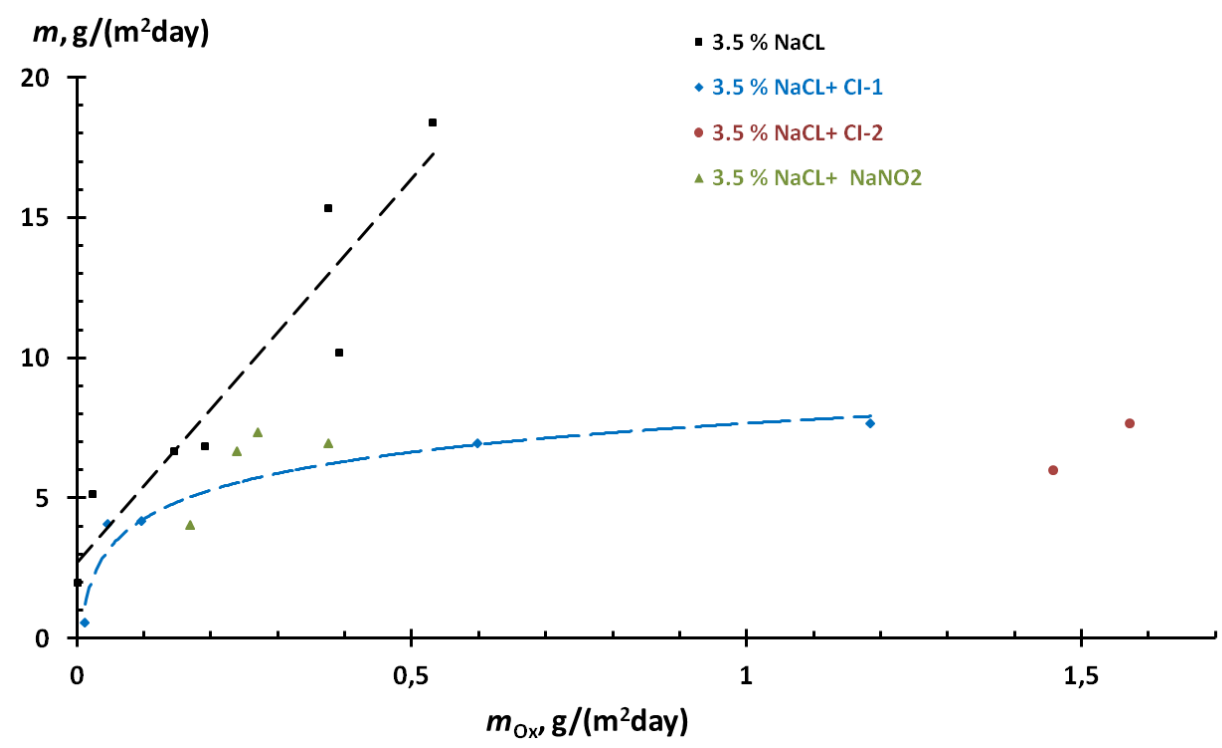

Figure 8. Comparison of the iron mass $m_{\mathrm{Ox}}$ in the products of $\mathrm{AC}$ steel corrosion in the form of $\mathrm{Fe}(\mathrm{II})$ compounds $v s$. the mass loss of steel $m$.

We believe that yet another explanation of this phenomenon can be provided, based on the different nature of iron passivity in the reference solution and in the presence of organic inhibitors. As shown elsewhere [42], iron is passivated in aqueous solutions of organic CIs without the formation of a surface layer consisting of $\mathrm{Fe}$ (III) oxides. In the cathodic AC halfcycle, CI particles are desorbed from the metal surface and iron dissolution occurs to give $\mathrm{Fe}(\mathrm{II})$ ions. Therefore, a layer of Fe(II) compounds is formed on the electrode surface. Susequently, Fe(II) compounds can be oxidized by molecular oxygen and the corrosion products consist of $\mathrm{Fe}(\mathrm{III})$ and $\mathrm{Fe}(\mathrm{II})$ compounds, but "oxide-free" passivation of organic CIs results in an increase in the fraction of the non-oxidized form. 
The addition of nitrite ions (i.e., an oxidative CI) to the solution also increases $m_{\mathrm{Ox}}$ (Figure 8) compared to the reference solution. It is evident that the oxidizer cannot slow down the oxidation of $\mathrm{Fe}$ (II) to $\mathrm{Fe}$ (III) or contribute to the formation of atomic hydrogen. Nevertheless, it has been shown that the presence of nitrite ions in alkaline chloridecontaining electrolyte favors the formation of a thicker and more compact passive film [49]. It is supposed that the increase in the film thickness occurs due to the reaction

$$
6 \mathrm{Fe}(\mathrm{OH})_{2}+2 \mathrm{NO}_{2}^{-} \rightarrow 2 \mathrm{Fe}_{2} \mathrm{O}_{4}+\mathrm{N}_{2} \mathrm{O}+2 \mathrm{OH}^{-}+5 \mathrm{H}_{2} \mathrm{O}
$$

As a result of reaction (3), the passive film is enriched with $\mathrm{Fe}(\mathrm{II})$ compounds [49]. It is evident that the growth of the amount of $\mathrm{Fe}$ (II) compounds in AC corrosion products in solutions containing $\mathrm{NO}_{2}{ }^{-}$ions may also be due to reaction [49] during the anodic half-cycle.

\section{Conclusions}

1. Under the effect of alternating current, corrosion inhibitors of both organic (CI-1 and CI-2) and inorganic (nitrite) types show roughly the same efficiency in the protection of carbon steel in $3.5 \% \mathrm{NaCl}$ solution. The protection degree changes in the range from 30 to $70 \%$, depending on the $\mathrm{AC}$ amplitude (peak potential values). In the absence of alternating current, the inhibitor protection degree is higher: 72,68 , and $56 \%$ for CI-1, CI-2, and nitrite, respectively.

2. The decrease in the inhibitor protective effect during AC corrosion is due to a decrease in the efficiency of inhibitors over time under conditions of intense metal dissolution. At comparable steel dissolution rates under potentiostatic polarization conditions ( $E=-0.15 \mathrm{~V}_{\mathrm{SHE}}$ ), the $Z$ value of the three CIs studied is roughly the same, $Z=52-54 \%$, which nearly coincides with the $Z=50-57 \%$ values during AC corrosion at the maximum peak potential value $(1.4 \mathrm{~V})$.

3. The concentration of $\mathrm{Fe}$ (II) compounds in $\mathrm{AC}$ corrosion products found by the coulometric oxidation method increases with an increase in steel mass loss. The linear correlation between these values observed in the reference chloride solution confirms the data reported previously [25]. In the presence of organic corrosion inhibitors, the concentration of $\mathrm{Fe}$ (II) compounds in the corrosion products grows considerably and no linear correlation with the steel mass loss is observed. It is assumed that the "oxide-free" metal passivation in the presence of organic corrosion inhibitors may be the reason of the increase in the amount of $\mathrm{Fe}$ (II) compounds in the AC corrosion products.

\section{References}

1. Y. Cui, T. Shen and Q. Ding, Study on the influence of AC stray current on X80 steel under stripped coating by electrochemical method, Int. J. Corros., 2019, 2019. doi: $10.1155 / 2019 / 4372430$

2. Y.T. Li, X. Li, G.W. Cai and L.H. Yang, Influence of AC interference to corrosion of Q235 carbon steel, Corros. Eng. Sci. Technol., 2013, 48, no. 5, 322-326. doi: $\underline{10.1179 / 1743278212 Y .0000000076}$ 
3. Q. Qin, B. Wei, Y. Bai, L. Nan, J. Xu, C. Yu and C. Sun, Effect of alternating current frequency on corrosion behavior of X80 pipeline steel in soil extract solution of Dagang, Int. J. Pressure Vessels Piping, 2020, 179, 104016. doi: 10.1016/j.ijpvp.2019.104016

4. A.I. Marshakov and T.A. Nenasheva, The effect of alternating current on rate of dissolution of carbon steel in chloride electrolyte. Part I. Conditions of Free Corrosion, Prot. Met. Phys. Chem. Surf., 2017, 53, 1214-1221. doi:10.1134/S2070205117070139

5. Z.Y. Liu, X.Z. Wang, C.W. Du, J.K. Li and X.G. Li, Effect of hydrogen-induced plasticity on the stress corrosion cracking of X70 pipeline steel in simulated soil environments, Mat. Sci. Eng. A, 2016, 658, 348-354. doi:10.1016/j.msea.2016.02.019

6. D.K. Kim, S. Muralidharan, T.H. Ha, J.H. Bae, Y.C. Ha, H.G. Lee and J.D. Scantlebury, Electrochemical studies on the alternating current corrosion of mild steel under cathodic protection condition in marine environments, Electrochim. Acta, 2006, 51, no. 25, 5259-5267. doi: 10.1016/j.electacta.2006.01.054

7. S. Muralidharana, D.K. Kim, T.H.Ha, J.H. Bae, Y.C.Ha, H.G. Lee and J.D. Scantlebury, Influence of alternating, direct and superimposed alternating and direct current on the corrosion of mild steel in marine environments, Desalination, 2007, 216, 103-115. doi: 10.1016/j.desal.2006.11.021

8. Q. Liu, W. Wu, Y. Pan, Z. Liu, X.C. Zhou and X.G. Li, Electrochemical mechanism of stress corrosion cracking of API X70 pipeline steel under different AC frequencies, Constr. Build. Mater., 2018, 171, 622-633. doi: 10.1016/j.conbuildmat.2018.03.209

9. L. Chen, Y. Du, Y. Liang and J. Li, Research on corrosion behavior of X65 pipeline steel under dynamic AC interference, Corros. Eng. Sci. Technol., 2021, 56, no. 3, 219-229. doi: $10.1080 / 1478422 X .2020 .1843819$

10. M.A. Maleeva, V.E. Ignatenko, A.V. Shapagin, A.A. Sherbina, L.B. Maksaeva, A.I. Marshakov and M.A. Petrunin, Modification of bituminous coatings to prevent stress corrosion cracking of carbon steel, Int. J. Corros. Scale Inhib., 2015, 4, no. 3, 226-234. doi: 10.17675/2305-6894-2015-4-3-226-234

11. I.M. Mousaa and H. Radi, Comparative studies of anticorrosion performance of novel inhibitors based on oleic acid and sulfur/nitrogen containing compounds in UV-curable coatings, Corros. Eng. Sci. Technol., 2017, 52, no. 7, 547-556. doi: 10.1080/1478422X.2017.1355657

12. Y. Feng and Y.F. Cheng, An intelligent coating doped with inhibitor-encapsulated nanocontainers for corrosion protection of pipeline steel, Chem. Eng. J., 2017, 315, 537-551. doi: 10.1016/j.cej.2017.01.064

13. V.E. Ignatenko, T. Vo, A.I. Marshakov, Yu.I. Kuznetsov, N.N. Andreev, A.V. Muradov and I.V. Ryakhovskikh, Effect of organic corrosion inhibitors on the crack growth rate in pipe steel X70 in weakly acidic solution, Int. J. Corros. Scale Inhib., 2019, 8, no. 1, 110-122. doi: $\underline{10.17675 / 2305-6894-2019-8-1-10}$ 
14. A. Rybkina, N. Gladkikh, A. Marshakov, M. Petrunin and A. Nazarov, Effect of signalternating cyclic polarisation and hydrogen uptake on the localised corrosion of X70 pipeline steel in near-neutral solutions, Metals, 2020, 10, no. 2, 245-252. doi: 10.3390/met10020245

15. A.B. Arabey, R.I. Bogdanov, V.E. Ignatenko and A.I. Marshakov, Effect of corrosion medium composition on rate crack growth in X70 pipeline steel, Prot. Met. Phys. Chem. Surf., 2011, 47, no. 2, 236-245. doi: 10.1134/S2070205111020031

16. R.N. Parkins, W.K. Blanchard, B.S. Delanty, Transgranular stress corrosion cracking of high-pressure pipelines in contact with solutions of near-neutral pH, Corrosion, 1994, 50, no. 5, 394-408.

17. X. Wang, C. Xu, Y. Chen, C. Tu, Z. Wang and X. Song, Effects of stray AC on corrosion of 3-layer polyethylene coated X70 pipeline steel and cathodic delamination of coating with defects in 3.5 wt-\% NaCl solution, Corros. Eng. Sci. Technol., 2018, 53, no. 3, 214-225. doi: $10.1080 / 1478422 X .2018 .1436736$

18. S.B. Lalvani, G. Zhang, The corrosion of carbon steel in a chloride environment due to periodic voltage modulation: Part II, Corros. Sci., 1995, 37, no. 10, 1583-1598.

19. R.W. Bosch and W.F. Bogaerts, A theoretical study of AC-induced corrosion considering diffusion phenomena, Corros. Sci., 1998, 40, no. 2-3, 323-336. doi: 10.1016/s0010-938x(97)00139-x

20. I. Ibrahim, B. Tribollet, H. Takenouti and M. Meyer, AC-Induced corrosion of underground steel pipelines. Faradaic rectification under cathodic protection: I. theoretical approach with negligible electrolyte resistance, J. Braz. Chem. Soc., 2015, 26, no. 1, 196-208. doi: $10.5935 / 0103-5053.20140246$

21. ISO 15589-1:2015(en), Petroleum, petrochemical and natural gas industries - Cathodic protection of pipeline systems - Part 1: On-land pipelines.

22. J. Riskin and A. Khentov, Electrocorrosion and Protection of Metals, Second Edition, Amsterdam, Elsevier, 2019, 396.

23. B. Wei, Q. Qin, Y. Bai, C. Yu, J. Xu, C. Sun and W. Ke, Short-period corrosion of X80 pipeline steel induced by AC current in acidic red soil, Eng. Failure Anal., 2019, 105, 156-175. doi: 10.1016/j.engfailanal.2019.07.014

24. Q. Qin, B. Wei, Y. Bai, L. Nan, J. Xu, C. Yu and C. Sun, Effect of alternating current frequency on corrosion behavior of X80 pipeline steel in soil extract solution of Dagang, Int. J. Pressure Vessels Piping, 2020, 179, 104016. doi: 10.1016/j.ijpvp.2019.104016

25. M. Büchler and H.G. Schöneich, Investigation of alternating current corrosion of cathodically protected pipelines: development of a detection method, mitigation measures, and a model for the mechanism, Corrosion, 2009, 65, no. 9, 578-586. doi: $\underline{10.5006 / 1.3319160}$

26. M. Büchler, Alternating current corrosion of cathodically protected pipelines: Discussion of the involved processes and their consequences on the critical interference values, Mater. Corros., 2012, 63, no. 12, 1181-1187. doi: 10.1002/maco.201206690 
27. L. Nielsen, K. Nielsen, B. Baumgarten and H. Breuning-Madsen, AC-induced corrosion in pipelines: Detection, characterisation and mitigation, Corrosion 2004, $2004,04211$.

28. A. Brenna, M. Ormellese and L. Lazzari, Corrosion 2013, 2013, 2457.

29. A.I. Marshakov and T.A. Nenasheva, The formation of corrosion defects upon cathodic polarization of X70 grade pipe steel, Prot. Met. Phys. Chem. Surf., 2015, 51, no. 7, 1122-1132. doi: $10.1134 /$ S2070205115070126

30. H. Wang, C. Du, Z. Liu, L. Wang and D. Ding, Effect of alternating current on the cathodic protection and interface structure of X80 steel, Materials, 2017, 10, no. 8, 851. doi: $10.3390 / \mathrm{ma10080851}$

31. S. Goidanich, L. Lazzari and M. Ormellese, AC corrosion. Part 1: Effects on overpotentials of anodic and cathodic processes, Corros. Sci., 2010, 52, no. 2, 491-497. doi: $\underline{10.1016 / j . c o r s c i .2009 .10 .005}$

32. S. Goidanich, L. Lazzari and M. Ormellese, AC corrosion. Part 2: Parameters influencing corrosion rate, Corros. Sci, 2010, 52, no. 3, 916-922. doi: 10.1016/j.corsci.2009.11.012

33. ASTM D1141-98(2013), Standard Practice for the Preparation of Substitute Ocean Water.

34. Y. Xu, Q. Zhou, L. Liu, Q. Zhang, S. Song and Y. Huang, Exploring the corrosion performances of carbon steel in flowing natural sea water and synthetic sea waters, Corros. Eng. Sci. Technol., 2020, 55, no. 7, 579-588. doi: 10.1080/1478422X.2020.1765476

35. E.O. Strandheim, AC Induced Corrosion of Carbon Steel in $3.5 \mathrm{wt} \% \mathrm{NaCl}$ Electrolyte, Norwegian University of Science and Technology Department of Materials Science and Engineering, 2012, 111.

36. G. Contreras, P. Fassina, G. Fumagalli, S. Goidanich, L. Lazzari and E. Mazzola, A study on metastability phenomena of passive films for corrosion resistant alloys, Electrochim. Acta, 2007, 52, no. 27, 7577-7584. doi: 10.1016/j.electacta.2006.12.037

37. S. Leeds, A review of what happens at the metal/electrolyte interface when cathodic protection is applied. What does this all means in terms of the protection criterion? 2013.

38. G. Sundjono, G. Priyotomo, L. Nuraini and S. Prifiharni, Corrosion behavior of mild steel in seawater from northern coast of java and southern coast of Bali, Indonesia, $J$. Eng. Technol. Sci., 2017, 49, no. 6, 770-784. doi: 10.5614/j.eng.technol.sci.2017.49.6.5

39. D.A. Jones, Principles and Prevention of Corrosion, Macmillan Publishing Company, 1992.

40. A.B. Arabei, N.N. Andreev, A.I. Marshakov and I.V. Ryakhovskikh, Inhibitor of corrosion and stress corrosion cracking, 2625382 C1 RU Patent,13072017 (in Russian).

41. Ya.G. Bober, Yu.I. Kuznetsov and N.P. Andreeva, Adsorption at iron and passivation effect of anions of substituted phenylanthranilic acids, Prot. Met., 2008, 44, no. 1, 8490. doi:10.1134/S0033173208010116

42. Yu.I. Kuznetsov, Organic Inhibitors of Corrosion of Metals, New York: Plenum Press, 1996, 283. 
43. Yu.I. Kuznetsov, N.N. Andreev and N.P. Andreeva, Synergistic effects in the inhibition of iron corrosion in neutral solutions, Prot. Met., 1998, 34, no. 1, 1-5.

44. Yu.I. Kuznetsov and N.P. Andreeva, On the coadsorption of mephenaminate and phenylundecanoate anions at passive iron, Prot. Met., 2005, 41, no. 6, 531-535. doi: 10.1007/s11124-005-0075-3

45. A.I. Altsibeeva and S.Z. Levin, Metal corrosion inhibitors, Leningrad, Khimiya, 1968, 264 (in Russian).

46. V.S. Sastri, Types of corrosion inhibitor for managing corrosion in underground pipelines. Underground Pipeline Corrosion, 2014, 166-211. doi: $\underline{10.1533 / 9780857099266.1 .166}$

47. H. Tian, W. Li, A. Liu, X. Gao, P. Han, R. Ding, C. Yang and D. Wang, Controlled delivery of multi-substituted triazole by metal-organic framework for efficient inhibition of mild steel corrosion in neutral chloride solution, Corros. Sci., 2018, 131, 1-16. doi: 10.1016/j.corsci.2017.11.010

48. Yu.I. Kuznetsov, I.A. Kuznetsov and D.B. Vershok, Copper corrosion protection in neutral media by dicarboxylic acid salt, Int. J. Corros. Scale Inhib., 2019, 8, no. 4, 1022-1034. doi: 10.17675/2305-6894-2019-8-4-13

49. M.A. Frontini, W. Schreiner, M. Vázquez and M.B. Valcarce, Nitrite corrosion inhibition in chloride-rich electrolytes correlated to the electrical properties of surface films on carbon steel, Constr. Build. Mater., 2019. 227, 116650. doi: 10.1016/j.conbuildmat.2019.08.031

50. M.B. Valcarce and M. Vazquez, Carbon steel passivity examined in alkaline solutions: The effect of chloride and nitrite ions, Electrochim. Acta, 2008, 53, no. 15, 5007-5015. doi: 10.1016/j.electacta.2008.01.091

51. F. Atmani, D. Lahem, M. Poelman, C. Buess-Herman and M.G. Olivier, Mild steel corrosion in chloride environment: effect of surface preparation and influence of inorganic inhibitors, Corros. Eng. Sci. Technol., 2013, 48, no. 1, 9-18. doi: 10.1179/1743278212Y.0000000037

52. C. Alonco, J. Fullea and C. Andrade, The risk of stress corrosion cracking of prestressed steel and its prevention by use of nitrite inhibitor, J. Corros. Sci. Eng., 2003, 6.

53. B.N. Popov, Corrosion Inhibitors, Ch. 14, Corrosion Engineering, 2015, 581-597.

54. T.A. Nenasheva, A.I. Marshakov and V.E. Ignatenko, The influence of alternating current on stress corrosion cracking of grade X70 pipe steel, Prot. Met. Phys. Chem. Surf., 2020, 56, no. 7, 1223-1231. doi: 10.1134/S2070205120070126

55. Yu.I. Kuznetsov, Organic corrosion inhibitors: where are we now? A review. Part II. Passivation and the role of chemical structure of carboxylates, Int. J. Corros. Scale Inhib., 2016, 5, no. 4, 282-318. doi: 10.17675/2305-6894-2016-5-4-1

56. CEN/TS 15280:2013, Evaluation of A.C. corrosion likelihood of buried pipelines Application to cathodically protected pipelines, Technical Specification (2013). 